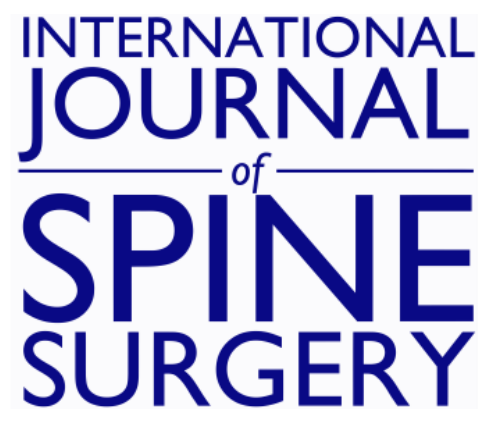

\title{
Innovations in Robotics and Navigation
}

Paul C. McAfee, Isador Lieberman and Nicholas Theodore

Int J Spine Surg 2021, 15 (s2) S7-S9

doi: https://doi.org/10.14444/8135

http://ijssurgery.com/content/15/s2/S7

This information is current as of April 26, 2023.

Email Alerts Receive free email-alerts when new articles cite this article. Sign up at: http://ijssurgery.com/alerts 


\title{
Innovations in Robotics and Navigation
}

\author{
PAUL C. MCAFEE, MD, MBA, ${ }^{1}$ ISADOR LIEBERMAN, MD, MBA, ${ }^{2}$ NICHOLAS THEODORE, $\mathrm{MD}^{3}$ \\ ${ }^{I}$ Chief of Spinal Research MedStar Union Memorial Spine Institute, Baltimore, Maryland, ${ }^{2}$ Scoliosis and Spine Tumor Center, Texas Back Institute, Plano, \\ Texas, ${ }^{3}$ Chief of Spine Surgery, Neurosurgery, Johns Hopkins Medical Center, Baltimore, Maryland
}

\section{CROSSING THE CHASM IN SPINAL ROBOTICS AND NAVIGATION}

With any emerging technology there is great anticipation and marketing; however, it is important that spinal surgeons who want cutting-edge treatment for their patients understand Everett $\mathrm{M}$. Rogers" "diffusion of innovations." In 1962 he outlined the theoretical participants who adopt innovative technologies and separated them into 5 distinct categories: innovators $(2.5 \%)$, early adopters $(13.5 \%)$, early majority $(34 \%)$, late majority $(34 \%)$, and laggards (16\%) (Figure 1). They are modeled in 5 progressive stages initially influenced by prior conditions yet ultimately directed by peerto-peer intercommunication: (1) knowledge, (2) persuasion, (3) decision, (4) implementation, and (5) confirmation. The distribution of adopters is usually a bell-shaped, not an S-shaped, curve. Some authors $^{2}$ have already compared the advent of spinal robotics to be as impactful as the industrial revolution and spinal navigation to be similar to the penetration of the cell phone. This is an embellished opinion as there have only been 3 innovations that have deviated from the bell-shaped curve of adoption and have seen an S-shaped diffusion curve, demonstrating exponential adoption: the personal computer, the internet, and cell phones.

This special issue of the International Journal of Spinal Surgery represents a distillation of only the very best articles. The goal of this issue is to reset the framework of innovation with the clear intention of stimulating discourse and encouraging creativity. This edition includes articles which in the near future will be considered the landmark articles that establish the place of spinal navigation and robotics.

Currently we are along the bell-shaped innovation curve at "the turning point"-Malcom Gladwell's "tipping point" or "the inflection point"-the space between the early adopters $(13.5 \%)$ and the early majority (34\%). This is described by Geoffrey A. Moore ${ }^{3}$ as "crossing the chasm." The most critical step in the technology of an innovative life cycle is making the transition between the visionaries (early adopters) and the pragmatists (early majority). It is not predictable to depend on innovators or early adopters because the group is too small and they are too quick to latch onto the next perceived innovation. Instead it is the early majority that is the decisive recruitment sectorthey are a larger group within the target population $(34 \%)$ and contain key opinion leaders that generate momentum and convey trust given their conservative approach to the remaining most risk-adverse cohorts. The challenge is that they are content with the traditional spinal technology they currently use for their patients. Fortunately, they are more dedicated and conscientious once they are convinced to change their practice.

This special issue, along with Part 2 coming out in 2022 , prove that spinal navigation and robotics has successfully "jumped the chasm." The complications and early learning curves are acceptable in several different institutional clinical series: Lieberman et al, Theodore et al, Campbell et al, etc. Several varied types of navigation have proved to be successful in the following peer-reviewed articlesDevito and Woo, Satin et al, Lieberman et al, and Theodore et al. Furthermore, Rossi and Coric's and Qureshi et al's articles on minimally invasive paraspinal surgical approaches for the cervical spine and lumbar spines give a glimpse into the power of these defining technologies. Other authors have claimed that spinal navigation and robotics have changed the definition of "standard of care." This concept is discussed in Satin et al's article. "Standard of care" is a legal definition and requires a broader multistate courtroom case-law track record. In contrast, Rossi and Coric provide a basis to consider cervical navigation the current state of 


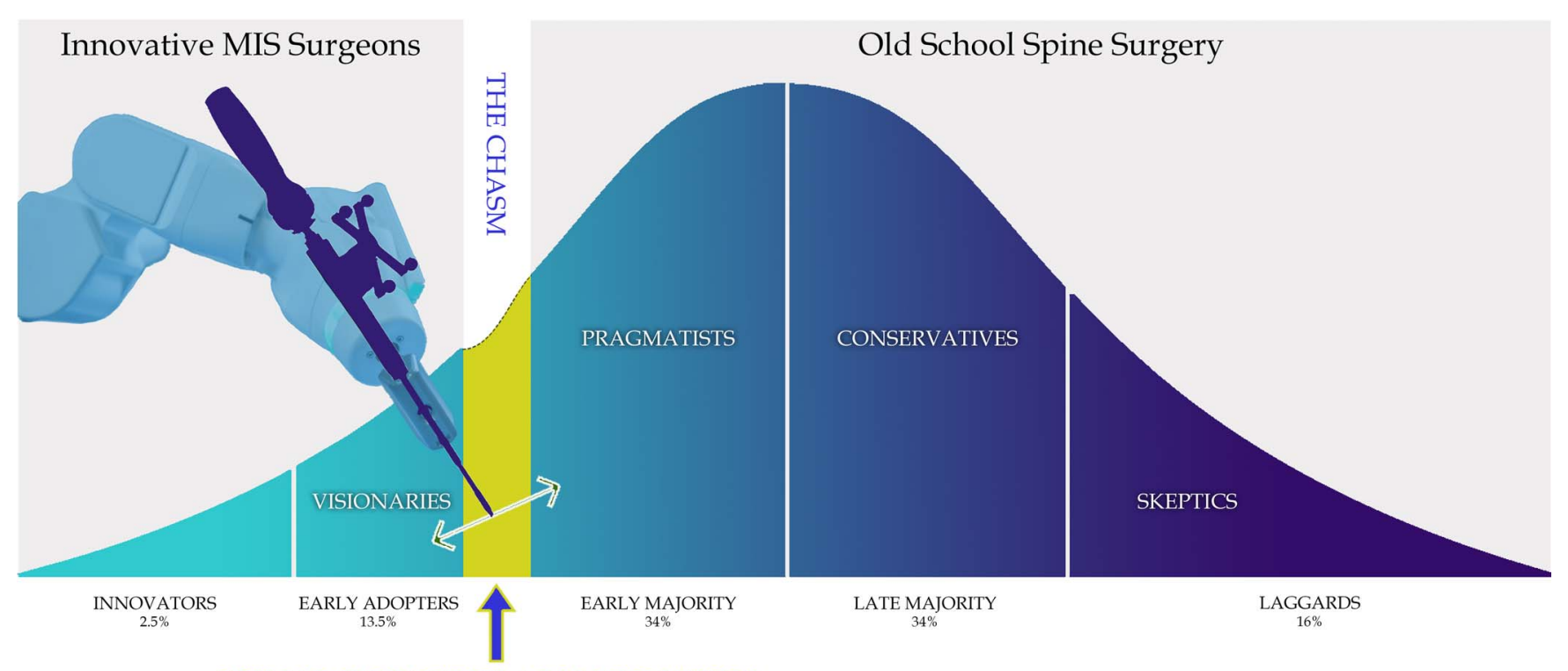

SPINAL ROBOTICS + NAVIGATION

Figure 1. The technology and precision of spinal robotics and navigation are currently at the inflection point in the innovation diffusion curve. The articles in this Focus issue are compelling enough to help minimally invasive surgical (MIS) techniques to cross the chasm from the early adopters to the early majority of fellowshiptrained spinal surgeons. ${ }^{6}$

the art. It is not possible to achieve and insert cervical pedicle screws of perfect trajectory, size, and length to the degree demonstrated in Coric's experience using only freehand techniques. The account of the largest cervical spine freehand pedicle screw experience was published by Abumi and Kaneda. ${ }^{4}$ The series from Rossi and Coric is smaller but his incidence of complications is less, and his length of hospitalization was less due to a paraspinal approach which Coric and Rossi show is less invasive to the paraspinal soft tissues.

Another expression of minimal invasiveness is lower radiation exposure. The work of Lieberman et al and Devito and Woo using Mazor X Stealth is very convincing. If there is any clear-cut expression of decreasing imaging and radiation requirements it is the performance of S2AI screws in deformity surgery. Using freehand techniques the surgeon requires anteroposterior, lateral, and teardrop fluoroscopic views repeatedly to probe, drill, and insert large pelvic screws, left and right sides, into the superior acetabular bone. This requires a minimum of 6 views for each side, whereas using navigation and/or robotics, the only imaging is that required for registration. The total radiation exposure to the patient and operative team is dramatically reduced.

The continuation of adoption of navigation and robotics is assured and there is plenty of room for growth and improvement in this space. The metaanalysis provided by Cunningham et al establishes the basic scientific accuracy of image guidance: 0.1 $\mathrm{mm}$ translation and $0.1 \mathrm{~mm}$ degree in optoelectronic laboratory conditions. This precision falls off in clinical application in the spine to 3 to $4 \mathrm{~mm}$ translation and 2 to 3 degrees of rotational accuracy. Total joint navigation and robotics currently lie between these two extremes. Total joint robotics has a presumed advantage in that it does not involve any viscoelastic joints, does not involve a series of 3 -joint complexes like the spine, and does not involve a series of chain linkages between the navigated bone and the skeletally anchored reference fiducials.

As predicted the intrinsic computed accuracy of the daVinci intracavitary robotic system is better than spine $(1.02 \mathrm{~mm})$ but still not to the level of Optotrak $3020(0.25 \mathrm{~mm}) .{ }^{5}$ DaVinci is a master-slave robot that does not use real-time optoelectronic camera tracking. Cunningham et al compared DaVinci to studies that have been done with cameras; however, this paradigm is not directly comparable to a real-time image-guided system that is used in spinal surgery. As they point out, a direct comparison of accuracy between these 2 different robotic systems is challenging as 2 different things are being compared (movement of a robotic arm in the case of the DaVinci and accuracy of screw placement in the case of a spine robot). While "accuracy" inferences can be made, a direct comparison between different robotic systems in different surgical subspecialties needs to take into 
account different definitions of "accuracy." daVinci systems are in their third generation-it is anticipated that the accuracy of spinal navigation and robotics will demonstrate similar improvements over the same time period with iterative improvements. As image guidance and robotics becomes more commonplace in spinal surgery, the improvements in workflow, accuracy, and patient outcomes will lead to further adoption as the chasm is fully crossed and we look forward to the next innovation which will almost certainly include bone removal automation allowing decompressive laminectomies and osteotomies to be performed with a high degree of accuracy in a rapid, reproducible fashion.

With the evolution of the multispecialty interventionalist, traditional surgical training will evolve and the next generation of surgeons will be far more accustomed to and accepting of the new technologies that are already present in their day-to-day lives.

The adoption will further be fueled by our millennial trainees who will not get as much time in the operating room as their predecessors and are quite facile with advanced technologies. Navigation and robotics are not yet the standard of care for spinal surgery. Spinal cord monitoring is not even the standard of care. Yet, the technology has definitely added a powerful tool into the surgical armamentarium and will continue to be improved upon with the addition of features that assist in a larger part of the surgery.
We hope that this special issue, along with the follow-up issue publishing in 2022, provides you with clinically relevant insights into the use of robotics and navigation in spine surgery.

\section{REFERENCES}

1. Rogers EM. Diffusion of Innovations. 5th ed. NewYork, NY: Free Press; 2003.

2. Walker CT, Kakarla UK, Chang SW. History and advances in spinal neurosurgery. J Neurosurg. 2019;31(6):775921.

3. Moore GA. Crossing the Chasm: Marketing and Selling Disruptive Products to Mainstream Customers. 3rd ed. New York, NY: HarperCollins; 2006.

4. Abumi K, Kaneda K. Pedicle screw fixation for nontraumatic lesions of the cervical spine. Spine. 1997,22(16):18531863.

5. Kwartowitz DM, Herrell SD, Galloway RL. Toward image-guided robotic surgery: determining intrinsic accuracy of the da Vinci robot. Urol Oncol. 2007;25(2):175-176.

6. McAfee PC. Spinal navigation and robotics-more precise, more accurate, and more minimally invasive. $A O$ Global Spine J. 2021; in press.

\section{Disclosures and COI: None}

Published 26 October 2021

This manuscript is generously published free of charge by ISASS, the International Society for the Advancement of Spine Surgery. Copyright (c) 2021 ISASS. To see more or order reprints or permissions, see http://ijssurgery.com. 